\title{
A FLUÊNCIA TECNOLÓGICO-PEDAGÓGICA DE PROFESSORES DE EDUCAÇÃO FÍSICA PARTICIPANTES DE UM CURSO ONLINE SOBRE REA
}

\author{
Maríndia Mattos Morisso - PPGE/UFSM - marindiamorisso@gmail.com \\ Tairone Girardon de Vargas - Unijuí - tairone vargas@hotmail.com \\ Elena Maria Mallmann - PPGE/UFSM - elena.ufsm@gmail.com
}

Resumo: Este artigo tem como objetivo analisar os impactos da adaptação e da produção de REA para a melhoria da fluência tecnológico-pedagógica de professores de Educação Física atuantes na educação básica do Rio Grande do Sul, participantes de um curso de formação continuada no Moodle. Os dados interpretados são resultados de dois ciclos de pesquisa-ação, ou seja, duas edições do curso (2018-2019). Cada ciclo ocorreu em quatro etapas: Planejamento - Ação- Observação - Reflexão. A análise da fluência tecnológico-pedagógica dos professores de Educação Física nas atividades do curso mostrou que apesar das dificuldades, as práticas de remix, adaptação ou produção de novos recursos ajudaram a melhorar a fluência e também colaboraram com a produção de materiais didáticos para o componente curricular.

Palavras-chave: REA, fluência tecnológico-pedagógica, educação física, educação básica.

\section{TECHNOLOGICAL-PEDAGOGICAL FLUENCE OF PHYSICAL EDUCATION TEACHERS PARTICIPATING IN AN ONLINE COURSE ON OER}

\begin{abstract}
This article aims to analyze the impacts of OER adaptation and production to improve the technological-pedagogical fluency of Physical Education teachers working in basic education in Rio Grande do Sul, participating in a continuing education course at Moodle. The interpreted data are results of two action research cycles, ie two editions of the course (2018-2019). Each cycle occurred in four steps: Planning - Action Observation - Reflection. The analysis of the technological-pedagogical fluency of Physical Education teachers in the course activities showed that despite the difficulties, the remix practices, adaptation or production of new resources helped to improve fluency and also contributed to the production of didactic materials for the curricular component.
\end{abstract}

Keywords: ORE, technological-pedagogical fluency, physical education, basic education.

\section{Introdução}

A integração das tecnologias educacionais na prática pedagógica de professores de Educação Física é considerada desafiadora para a área, pois, tradicionalmente ela foi reconhecida como um componente curricular exclusivamente prático e sem conteúdo (DARIDO et. al, 1999). Apesar disso, ao longo dos anos, documentos curriculares apontaram que o objeto de estudo da Educação Física é a cultura corporal de movimento. Os Parâmetros Curriculares Nacionais - PCNs (1998), as Lições do Rio Grande (2009), a Base Nacional Comum Curricular - BNCC (2018) e atualmente, em implementação, o Referencial Curricular Gaúcho (2018) definem que a finalidade do componente curricular é introduzir o aluno a temas que fazem parte da cultura corporal de movimento, compreendendo seu contexto histórico que também está vinculado ao campo do lazer e da saúde. 
Considerando as orientações sobre o que ensinar, entendemos que a integração das tecnologias educacionais no componente curricular poderia colaborar com $\mathrm{o}$ reconhecimento da área. Morisso, Vargas e Mallmann (2017) apontaram algumas alternativas para essa integração, a partir da (re)formulação da Educação Física no ensino médio de uma escola pública. Nessa pesquisa, materiais didáticos foram produzidos em colaboração entre os pesquisadores e uma professora participante, com a mediação das tecnologias. Dentre outros aspectos, foi concluído que, a docente apresentava pouca fluência tecnológico-pedagógica.

Segundo Schneider (2011, p. 82) "Ser fluente tecnologicamente significa conhecer e apropriar-se das ferramentas educacionais, seus princípios e aplicabilidade em diferentes situações". Portanto, avaliando a necessidade da área em produzir materiais didáticos para romper com a tradição ligada ao saber fazer e corresponder aos objetivos apresentados nos documentos orientadores é importante que os docentes compreendam princípios e características dos Recursos Educacionais Abertos (REA), que são "[...] materiais de suporte à educação que podem ser acessados, reutilizados, modificados e compartilhados livremente" (UNESCO, 2015, p. 1). O conhecimento sobre REA e o desenvolvimento da fluência tecnológico-pedagógica podem colaborar para a valorização dos profissionais da educação desse campo curricular além de contribuir com o reconhecimento da Educação Física, reconhecendo, inclusive seus saberes conceituais.

Diante disso, neste trabalho temos o objetivo de analisar os impactos da adaptação e da produção de REA para a melhoria da fluência tecnológico-pedagógica de professores de Educação Física atuantes na educação básica. São docentes, participantes de um curso de formação continuada online, um Small Open Online Course - SOOC no Moodle, oferecido para professores e servidores da rede pública de educação básica do Rio Grande do Sul. Esse estudo possibilita também avaliar as potencialidades dos REA para a produção e o compartilhamento de materiais didáticos entre professores de Educação Física a fim de corresponder aos objetivos previstos para a área em documentos orientadores como a BNCC e o Referencial Curricular Gaúcho.

\section{Material e Métodos}

Os dados apresentados neste artigo são resultados de dois ciclos de uma pesquisa-ação, que consistiu na elaboração/revisão, desenvolvimento e análise dos resultados de um curso de formação continuada, totalmente online. O curso REA: Educação para o Futuro foi realizado em duas edições: no $2^{\circ}$ semestre de 2018 e no $1^{\circ}$ semestre de 2019, em formato de SOOC, pelo Grupo de Pesquisa GEPETER da UFSM (Grupo de Estudos e Pesquisas em Tecnologias Educacionais em Rede).

O SOOC consiste em um curso online com inscrição aberta, mas com um número reduzido de participantes, o que facilita a interação entre professores e tutores (SHIMABUKURO, 2013). Segundo Mazzardo, Nobre e Mallmann (2017, p. 179) "As características do SOOC possibilitam a adoção de recursos educacionais e concepções pedagógicas diversificadas, que podem ser exploradas na formação de professores, em diversos contextos, para responder a necessidades específicas". O SOOC/Curso REA: Educação para o Futuro foi oferecido para professores e servidores atuantes em diferentes áreas da rede pública de educação básica do RS, que, a partir de um convite puderam se inscrever. Entretanto, neste momento, apresentamos apenas resultados das participações de professores da área de Educação Física, de acordo com os objetivos de um projeto de tese que está sendo elaborado para um Programa de Pós-Graduação em Educação. 
O curso foi organizado em quatro Unidades. A Unidade I - Recursos Educacionais Abertos - introduziu o tema e questionou os participantes sobre o que eles sabiam em relação aos REA a as licenças abertas. A Unidade II - Direitos Autorais e Licenças Abertas - apresentou a Lei dos Direitos Autorais (Lei brasileira, 9.610/98), as Licenças Abertas como Creative Commons, GNU General Public License, Copyleft e obras de Domínio Público. A Unidade III - Organização de Material Didático Aberto discutiu sobre a identificação da abertura legal e técnica dos recursos e solicitou a adaptação ou remix de um REA. Por fim, na Unidade IV - Produção e Compartilhamento de REA - os participante foram orientados a produzir e a compartilhar um REA de sua autoria.

De acordo com Elliott (1978) a pesquisa-ação tem interesse nos problemas vivenciados por professores no desenvolvimento da prática pedagógica. Portanto, considerando a necessidade de legitimar a Educação Física enquanto componente curricular que possui conhecimento e verificando a falta de materiais didáticos para a área, entendemos que um curso de formação continuada sobre REA poderia colaborar como alternativa para amenizar o problema.

Segundo Carr e Kemmis (1986) a pesquisa-ação é uma forma de auto-reflexão em que os participantes buscam melhorar a atuação profissional. Portanto, um curso como o REA: Educação para o Futuro ao potencializar a fluência tecnológicopedagógica dos participantes, pode motivá-los a produzir e a compartilhar conhecimento, mediados pelas tecnologias.

Consideramos cada edição do curso um ciclo da pesquisa-ação. Os ciclos foram divididos em quatro etapas: a Etapa 1 - Planejamento: consistiu na elaboração do curso ( $1^{\mathrm{a}}$ edição) e revisão/modificações do curso ( $2^{\mathrm{a}}$ edição); a Etapa 2 - Ação: tratou da implementação do curso; a Etapa 3 - Observação: ocorreu durante a tutoria da qual participamos; e a Etapa 4, que discutimos neste artigo, Reflexão - foi a análise da fluência tecnológico-pedagógica dos professores de Educação Física nas atividades das Unidades III e IV.

Portanto, conforme já destacado, analisamos neste artigo a última etapa dos dois ciclos da pesquisa-ação, a Reflexão. Sendo assim, discutimos sobre a fluência tecnológico-pedagógica em seis REA adaptados/remixados e dez REA produzidos, por 13 professores de Educação Física que concluíram o curso. Cabe considerar que na $1^{\mathrm{a}}$ edição todos tiveram que realizar as duas atividades, de adaptação/remix e produção de REA, assim, tivemos a participação de cinco professores (dois realizaram as atividades em dupla). Já na $2^{\mathrm{a}}$ edição os participantes tiveram a opção de escolher se preferiam realizar uma adaptação/remix ou produção de REA, então, contamos com a colaboração de oito professores. No Quadro 1 apresentamos essa relação.

Quadro 1 - Relação de participantes que realizaram a adaptação/remix ou a produção de REA nas duas edições do curso

\begin{tabular}{|l|l|l|l|}
\hline \multicolumn{2}{|c|}{$\mathbf{1}^{\mathbf{a}}$ Edição } & \multicolumn{2}{c|}{$\mathbf{2}^{\mathbf{a}}$ Edição } \\
\hline Adaptação/remix & Produção & Adaptação/remix & Produção \\
\hline Participantes 1-2 & Participantes 1-2 & Participante 6 & Participante 8 \\
\hline Participante 3 & Participante 3 & Participante 7 & Participante 9 \\
\hline Participante 4 & Participante 4 & & Participante 10 \\
\hline Participante 5 & Participante 5 & & Participante 11 \\
\hline & & & Participante 12 \\
\hline & & & Participante 13 \\
\hline
\end{tabular}

Fonte: Os autores 
A interpretação dos dados seguiu a análise de conteúdo de Bardin (2011). Segundo a autora, "a analise de conteúdo aparece como um conjunto de técnicas de análise das comunicações que utiliza procedimentos sistemáticos e objetivos de descrição do conteúdo das mensagens" (BARDIN, 2011, p. 44). Nesse caso em específico, analisamos os dados buscando compreender como os materiais produzidos e adaptados pelos professores estão articulados com os documentos que orientam "o que ensinar?" na Educação Física Escolar (BNCC e o Referencial Curricular Gaúcho), bem como sua aplicabilidade na prática docente, caracterizando ou não uma apropriação e coautoria, ou seja, uma fluência tecnológico-pedagógica.

\section{Resultados e Discussão}

A adaptação/remix e a produção de REA por professores de Educação Física é importante para que o componente curricular possa ter materiais didáticos elaborados a partir da prática diária dos docentes disponibilizados de forma aberta. Segundo Mazzardo (2018, p. 2) "os REA possibilitam ao professor a condição de organizador e autor de material didático aberto, sendo que estas são ações inovadoras em um contexto em que predominam os materiais didáticos com direitos autorais". O reconhecimento da autoria dos professores motiva no planejamento das aulas. Nesse contexto, a fluência tecnológico-pedagógica é necessária, pois, "Operar com fluência, no sentido de compreender, colaborativamente, é essencial para criar, modificar e compartilhar problematizações dialógico-problematizadoras em situações-limite, caminho para a emancipação (autonomia, autoria e coautoria)" (SCHNEIDER, MALLMANN, FRANCO, 2015, p. 157) .

A partir das adaptações/remix e produções de REA de professores participantes do SOOC observamos dificuldades dos docentes para concluírem as atividades, fato que pode estar relacionado a pouca fluência tecnológico-pedagógica. Dos critérios solicitados, a atribuição da licença e o compartilhamento do recurso em um repositório foram os que os docentes tiveram maior dificuldade para contemplar. Com relação ao conteúdo, houve a predominância do Jogo Motor, porém a maioria dos docentes não deixou claro em que contexto (turma/ano e objetivo) iria utilizá-lo.

A Unidade III - Material Didático Aberto, tinha como objetivos: Identificar a Abertura Legal e Técnica dos recursos; Adaptar/remixar REA para uma realidade educacional; Organizar material didático com REA; Compartilhar o REA adaptado/remixado; Melhorar a fluência tecnológico-pedagógica dos professores. Para corresponder a esses objetivos solicitamos em uma atividade que os cursistas adaptassem um REA existente. Todos deveriam seguir o seguinte roteiro: 1) Selecionar um REA com licença que permitisse produção de obra derivada; 2) Adaptar/modificar para o contexto da sua realidade escolar; 3) Postar no fórum do curso o endereço do REA original e anexar o arquivo do REA adaptado (ou o endereço se o REA adaptado fosse disponibilizado em um drive ou repositório).

Podemos observar que fluência tecnológico-pedagógica nessa atividade ocorre quando os participantes são desafiados a trabalhar de forma colaborativa, tornando-se coautores de um REA existente. Portanto, os docentes que costumavam buscar recursos na internet para contribuir com suas aulas, foram desafiados a modificar o REA assumindo a condição de coautor. A adaptação realizada para cada contexto com a informação de que o recurso foi adaptado por outros sujeitos e a publicação do novo REA são características da fluência tecnológico-pedagógica.

Apresentamos no Quadro 2 uma síntese da atividade referente a Unidade III que foi realizada por sete participantes, professores de Educação Física nas duas edições do 
curso. Conforme podemos visualizar, foram elaboradas seis adaptações (dois participantes realizaram a atividade em dupla). No Quadro observamos que há três atividades, uma sequência didática, uma imagem e um guia. As atividades são classificadas na Educação Física como Jogo Motor e foram adaptadas do Blog: Acervo Educarede (http://www.aberta.org.br/educarede/) que possui licença Creative Commons - Atribuição-Não Comercial (CC BY-NC). A sequência didática é uma adaptação da Plataforma Anísio Teixeira (http://pat.educacao.ba.gov.br/). O documento original possui licença Creative Commons - Atribuição-Não Comercial-Compartilhar Igual (CC BY-NC-SA). A imagem foi adaptada de uma atividade disponível na plataforma MEC RED com licença Creative Commons - Atribuição-Não Comercial-Compartilhar Igual (CC BY-NC-SA). Já o Guia é uma produção de Criativos da Escola e também possui licença Creative Commons - Atribuição-Não Comercial-Compartilhar Igual (CC BY-NC-SA). Portanto todos os participantes escolheram REA que permitiam obra derivada.

Quadro 2 - Resultado da atividade de Adaptação de REA realizada pelos Participantes

\begin{tabular}{|c|c|c|c|}
\hline Participantes & Link do REA original & Tipo & $\begin{array}{l}\text { Classificação na } \\
\text { Educação } \\
\text { Física/Nome ou } \\
\text { tema }\end{array}$ \\
\hline Participantes 1-2 & $\begin{array}{l}\text { http://www.aberta.org.br/educarede/2013/0 } \\
\text { 5/27/pega-pega-colorido/ }\end{array}$ & Atividade & $\begin{array}{l}\text { Jogo Motor/Pega- } \\
\text { Pega Colorido }\end{array}$ \\
\hline Participante 3 & $\begin{array}{l}\text { http://pat.educacao.ba.gov.br/conteudos- } \\
\text { digitais/conteudo/exibir/id/2426 }\end{array}$ & $\begin{array}{l}\text { Sequência } \\
\text { Didática }\end{array}$ & $\begin{array}{l}\text { Práticas Corporais } \\
\text { e Sociedade ou } \\
\text { Práticas Corporais } \\
\text { e Saúde/DSTs }\end{array}$ \\
\hline Participante 4 & $\begin{array}{l}\text { http://www.aberta.org.br/educarede/2013/0 } \\
\text { 5/23/painel-de-jogos/ }\end{array}$ & Atividade & $\begin{array}{l}\text { Jogo Motor/Painel } \\
\text { de Jogos }\end{array}$ \\
\hline Participante 5 & $\begin{array}{l}\text { http://www.aberta.org.br/educarede/2013/0 } \\
\text { 5/23/desafios-grupais-com-cordas/ }\end{array}$ & Atividade & $\begin{array}{l}\text { Jogo } \\
\text { Motor/Desafios } \\
\text { Grupais com } \\
\text { Cordas }\end{array}$ \\
\hline Participante 6 & $\begin{array}{l}\text { https://plataformaintegrada.mec.gov.br/rec } \\
\underline{\text { urso?id=18509\&name=Caminhando } \% 20 \text { so }} \\
\underline{\text { bre } \% 20 \mathrm{a} \% 20 \text { linha }}\end{array}$ & Imagem & $\begin{array}{l}\text { Jogo Motor/ } \\
\text { Caminhando sobre } \\
\text { Cordas }\end{array}$ \\
\hline Participante 7 & $\begin{array}{l}\text { https://criativosdaescola.com.br/wp- } \\
\text { content/uploads/2015/07/Guia-de- } \\
\text { Viagem_Vers\%C3\%A3o2018_Site.pdf }\end{array}$ & $\begin{array}{l}\text { Guia de } \\
\text { Viagem }\end{array}$ & $\begin{array}{l}\text { Práticas Corporais } \\
\text { e Sociedade ou } \\
\text { Práticas Corporais } \\
\text { e Saúde/Sonhos e } \\
\text { identidade }\end{array}$ \\
\hline
\end{tabular}

Fonte: os autores.

Nas seis adaptações é possível observar alterações dos professores para que os REA correspondessem ao contexto onde trabalham. Os Participantes 1-2, 3, 4, 6 e 7 não informaram uma turma específica em que gostariam de utilizar o REA adaptado, mantiveram as informações do original, referentes ao ensino fundamental, ensino médio ou nenhuma referência. Somente o Participante 5 definiu que seu recurso seria utilizado nas turmas de $5^{\circ}$ e $6^{\circ}$ ano. Além disso, os participantes 5, 6 e 7 inseriram seu nome no 
documento do REA adaptado, assumindo assim o papel de coautores, os demais mantiveram apenas o nome dos autores do recurso original.

Em geral os REA adaptados contribuem com a prática pedagógica dos docentes participantes da pesquisa. No Referencial Curricular Gaúcho que está de acordo com a BNCC os Jogos Motores (presentes nos REA dos participantes 1-2, 4, 5 e 6) estão incluídos na Unidade Temática denominada Jogos e Brincadeiras do $1^{\circ}$ ao $7^{\circ}$ ano do ensino fundamental. Os Jogos e Brincadeiras na BNCC "[...] têm valor em si e precisam ser organizados para ser estudados [eles] trazem consigo formas de conviver, oportunizando o reconhecimento de seus valores e formas de viver em diferentes contextos ambientais e socioculturais brasileiros" (p. 215). Portanto, não devem ser apresentadas como atividades isoladas e desconectadas de um plano de ensino, mas sim, fazer parte de um projeto maior que contemple a Unidade Temática como um dos conteúdos abordados no componente curricular.

As adaptações dos Participantes 3 e 7 estão mais relacionadas a um tema transversal descrito nas Lições do Rio Grande (2009), Práticas Corporais e Sociedade ou Práticas Corporais e Saúde. A Participante 3 informou que utilizaria o REA na sua prática, em aulas do ensino médio, já a Participante 4 destacou que sua intenção era trabalhar nas disciplinas de Artes e Educação Física com o REA adaptado.

Com relação ao item 3 da atividade: Postar no fórum do curso o endereço do REA original e anexar o arquivo do REA adaptado (ou o endereço se o REA adaptado fosse disponibilizado em um drive ou repositório), observamos que os Participantes 5, 6 e 7 realizaram de forma completa e correta. Os Participantes 1-2 e 4 postaram o documento com as adaptações, mas informaram apenas o link do repositório, não do REA (tivemos que buscá-lo a partir do nome do recurso). O Participante 3 apresentou sua adaptações diretamente no fórum e também informou apenas o link do repositório em que se encontrava o REA.

Relacionando os conceitos de REA com o currículo da Educação Física, podemos interpretar que a fluência tecnológico-pedagógica tem uma importante função na relação planejamento, materiais didáticos e tecnologias educacionais. Segundo Mallmann, Schneider e Mazzardo (2013, p. 05) a fluência tecnológico-pedagógica pode ser conceituada "como a capacidade de mediar o processo de ensino-aprendizagem com conhecimentos sobre planejamento, estratégias metodológicas, conteúdos, material didático, tecnologias educacionais em rede [...]". Nesse sentido, compreendemos que a adaptação dos REA pelos professores de Educação Física correspondem aos objetivos propostos nos documentos curriculares sobre o que ensinar. As atividades adaptadas explicam metodologicamente como ensinar, além de que as tecnologias educacionais estão presentes no planejamento e também como recurso para contribuir como o processo de ensino-aprendizagem. Essas informações indicam que a melhoria da fluência tecnológico-pedagógica pode ser desenvolvida através da utilização de REA.

A Unidade IV - Produção e Compartilhamento de REA tinha os objetivos de: Produzir REA; Compartilhar os REA selecionados, adaptados/remixados e produzidos; Organizar material didático com REA; Fomentar a integração de REA nas práticas didáticas dos professores da Educação Básica; Melhorar a fluência tecnológicopedagógica dos professores da Educação Básica. Diante disso, a atividade solicitada aos cursistas foi a criação de um REA original, seguindo o roteiro: 1) Verificar as orientações sobre como criar um REA (no conteúdo da Unidade IV); 2) Criar um REA; 3) Compartilhar o REA no fórum, anexando o arquivo do REA produzido ou o link do repositório escolhido. No Quadro 3 apresentamos uma síntese dos REA produzidos pelos Participantes. 
Quadro 3 - Resultado da atividade de Produção de REA realizada pelos Participantes

\begin{tabular}{|c|c|c|c|}
\hline Participantes & Link do REA & Tipo & $\begin{array}{l}\text { Classificação na } \\
\text { Educação Física/Nome }\end{array}$ \\
\hline Participantes 1-2 & $\begin{array}{l}\text { Enviou a plataforma MEC RED, } \\
\text { mas ainda não foi publicado. }\end{array}$ & Plano de aula & $\begin{array}{l}\text { Esporte/ Circuito de } \\
\text { atividades para } \\
\text { treinamento da } \\
\text { modalidade esportiva } \\
\text { voleibol. }\end{array}$ \\
\hline Participante 3 & $\begin{array}{l}\underline{\text { https://sites.google.com/view/cartil }} \\
\text { hadedigitaledfisica/p\%C3\%A1gina- } \\
\text { inicial }\end{array}$ & Repositório & Esporte e Ginástica. \\
\hline Participante 4 & $\begin{array}{l}\text { Não compartilhou em nenhum } \\
\text { repositório. }\end{array}$ & Texto & $\begin{array}{l}\text { Não apresenta nenhuma } \\
\text { relação direta com a } \\
\text { Educação Física. }\end{array}$ \\
\hline Participante 5 & $\begin{array}{l}\text { Não compartilhou em nenhum } \\
\text { repositório. }\end{array}$ & Plano de aula & $\begin{array}{l}\text { Ginástica - Exercício } \\
\text { Físico/ Cuidados para } \\
\text { Jovens Iniciantes na } \\
\text { Prática de Atividades } \\
\text { Físicas. }\end{array}$ \\
\hline Participante 8 & $\begin{array}{l}\text { Não compartilhou em nenhum } \\
\text { repositório. }\end{array}$ & $\begin{array}{l}\text { Sequência } \\
\text { didática }\end{array}$ & Jogo Motor/Jogo do Taco. \\
\hline Participante 9 & $\begin{array}{l}\text { Enviou a plataforma MEC RED, } \\
\text { mas ainda não foi publicado. }\end{array}$ & $\begin{array}{l}\text { Sequência } \\
\text { didática }\end{array}$ & Lutas. \\
\hline Participante 10 & $\begin{array}{l}\text { Não compartilhou em nenhum } \\
\text { repositório. }\end{array}$ & $\begin{array}{l}\text { Sequência } \\
\text { didática }\end{array}$ & Esporte/Rugby. \\
\hline Participante 11 & $\begin{array}{l}\text { https://pt.slideshare.net/MarcosCair } \\
\underline{\text { ro/aula-sobre-obesidade-151977161 }}\end{array}$ & Apresentação & $\begin{array}{l}\text { Ginástica - Exercício } \\
\text { Físico/Obesidade. }\end{array}$ \\
\hline Participante 12 & $\begin{array}{l}\text { Não compartilhou em nenhum } \\
\text { repositório. }\end{array}$ & Apresentação & $\begin{array}{l}\text { Esporte/Considerações à } \\
\text { compreensão do jogo de } \\
\text { Futebol. }\end{array}$ \\
\hline Participante 13 & $\begin{array}{l}\text { Não compartilhou em nenhum } \\
\text { repositório. }\end{array}$ & Avaliação & $\begin{array}{l}\text { Ginástica - Exercício } \\
\text { Físico. }\end{array}$ \\
\hline
\end{tabular}

Fonte: os autores.

Como dialogamos anteriormente, para que o recurso seja considerado REA é importante que os autores atribuam a ele algum tipo de licença aberta, no caso do curso, trabalhamos com as licenças Creative Commons. Observamos que apenas o Participante 4 não atribui nenhuma licença ao material que produziu, solicitamos a correção, porém ele não voltou a responder. Os outros onze REA produzidos apresentam licenças diferentes, tais como: CC BY; CC BY-NC; CC BY-NC-ND; CC BY-NC-SA.

Os Participantes 4, 5, 8, 10, 12 e 13 não compartilharam seus materiais em nenhum repositório e não informaram se pretendiam fazer isso em algum momento, apesar de terem sido questionados. Os Participantes 1-2 e 9 destacaram que seus REA foram enviados a Plataforma MEC RED e que aguardam a publicação. O Participante 3 V. $17 \mathrm{~N}^{\mathrm{o}}$ 3, dezembro, 2019 RENOTE DOI: 
criou um site/repositório para compartilhar com outros professores materiais alternativos para a Educação Física, chamado de Cartilha. No site recebe sugestões de materiais de outros professores que estejam interessados a contribuir. São materiais que auxiliam na prática de modalidades esportivas e de ginástica. Já o Participante 11 publicou sua apresentação no site SlideShare e compartilhou o link no fórum da atividade.

A partir da análise dos REA produzidos pelos Participantes do curso constatamos que os conteúdos apresentados fazem parte do currículo da Educação Física. Diante desse contexto, questionamos sobre as dificuldades dos docentes realizarem as atividades de forma completa, visto que, os materiais apresentados fazem parte da sua prática diária. Entretanto, cabe considerar que o problema maior dos professores foi tornar seu material público para além do Moodle, ou seja, autorizar pessoas desconhecidas a explorar a sua produção, fato que pode ser modificado com a melhoria da fluência tecnológico-pedagógica, conforme os estudos citados (SCHNEIDER, 2011; MALLMANN, SCHNEIDER, MAZZARDO, 2013; SCHNEIDER, MALLMANN, FRANCO, 2015).

Os dados destes ciclos de pesquisa-ação mostraram que a adaptação e a produção de REA estão diretamente ligadas a fluência tecnológico-pedagógica. Compreendemos que a necessidade dos docentes refletirem sobre as suas práticas pedagógicas e buscar alternativas para contribuir com o processo de ensinoaprendizagem potencializa a produção de conhecimento de forma colaborativa podendo se reconhecer como autor e coautor de materiais didáticos através dos REA.

\section{CONCLUSÕES}

A adaptação e a produção de REA por professores de Educação Física atuantes na educação básica é uma importante alternativa para contribuir com duas situações: 1) a produção de materiais didáticos para o componente curricular e 2) o desenvolvimento da fluência tecnológico-pedagógica e, consequentemente, o próprio desenvolvimento profissional. O Curso REA: Educação para o Futuro mostrou que o conhecimento dos docentes sobre REA contribui para a inovação didático-metodológica dos participantes e indicou que é possível pensar a produção colaborativa de materiais didáticos para a área, desenvolvendo ao longo desse processo a fluência tecnológico-pedagógica.

As adaptações e as produções de REA dos participantes apresentaram relações com os documentos curriculares que orientam o que ensinar na Educação Física Escolar. Em geral eles contemplam principalmente as Unidades Temáticas de Jogos e Brincadeiras, Esporte, Ginástica de Condicionamento Físico e Lutas.

Os REA, presentes no contexto de adaptação e produção de planos de aula, sequência didática e atividades, têm como consequência a elaboração e compartilhamento de materiais didáticos abertos através das tecnologias educacionais. Portanto, a prática das cinco liberdades dos REA (reter, reutilizar, remixar, readaptar, recompartilhar) apresentam importantes contribuições para a troca de experiências e produção de conhecimento para o componente curricular, oferecendo aos docentes, possiblidades para discutir sobre como ensinar o que orientam os documentos curriculares.

O processo de criação de novas metodologias, estratégias e formas de ensinar colaborativamente através das tecnologias educacionais condizem com 0 desenvolvimento da fluência tecnológico-pedagógica. Por isso, os REA também apresentam contribuições nesse sentido. $\mathrm{O}$ exercício de verificar o grau de abertura do 
material e de como ele pode ser adaptado ou compartilhado é uma forma de integrar as tecnologias na prática pedagógica como aliadas no processo de ensino-aprendizagem.

Sendo assim, interpretamos que a formação continuada realizada ao longo do Curso REA: Educação para o Futuro contribuiu para o desenvolvimento da fluência tecnológico-pedagógica de professores de Educação Física da rede pública de educação básica do RS. Além disso, a adaptação e a produção de REA para o contexto em que os docentes trabalham faz refletir sobre a prática pedagógica, tendo como consequência a inovação didático-metodológica. Dessa forma, o componente curricular ganha com materiais didáticos e produção de conhecimento a partir da autoria e coautoria dos próprios professores.

\section{Agradecimentos}

A FAPERGS que apoia o projeto: "Formação de professores da educação básica no RS: inovação didático-metodológica mediada por Recursos Educacionais Abertos (REA)", sendo o Curso REA: Educação para o Futuro, uma das ações desenvolvidas.

O presente trabalho foi realizado com apoio da Coordenação de Aperfeiçoamento de Pessoal de Nível Superior - Brasil (CAPES) - Código de Financiamento 001.

\section{REFERÊNCIAS}

BARDIN, L. Análise de conteúdo. Tradução: Luís Antero Reto e Augusto Pinheiro. São Paulo: Edições 70, 2011.

BRASIL. Parâmetros curriculares nacionais. Secretaria de Educação Fundamental:

Educação Física / Secretaria de Educação Fundamental. Brasília: MEC / SEF, 1998. 114 p. Disponível em: < http://portal.mec.gov.br/seb/arquivos/pdf/fisica.pdf $>$ Acesso em: 12 set. 2016.

BRASIL. Base Nacional Comum Curricular. 2018. Disponível em $<\mathrm{http}$ ://basenacionalcomum.mec.gov.br/wpcontent/uploads/2018/12/BNCC_19dez2018_site.pdf>. Acesso em: 02 abr. 2019.

CARR, W.; KEMMIS, W. Becoming critical education: knowledge and action research. London and Philadelphia: The Palmer Press, 1986.

DARIDO, S. C. et al. Educação Física no Ensino Médio: Reflexões e Ações. Motriz-v. 5, Número 2, Dezembro/1999. Disponível em: $<$ http://www.rc.unesp.br/ib/efisica/motriz/05n2/5n202Darido.pdf $>$ Acesso em: 30 mai. 2016.

ELLIOTT, J. What is Action-Research in Schools? Journal of Curriculum Studies. Vol.10, nº 4 : 3357, 1978.

MALLMANN, E. M; SCHNEIDER, D. R; MAZZARDO, M. D. Fluência TecnológicoPedagógica (FTP) dos Tutores. CINTED-UFRGS Novas Tecnologias na Educação. V. $11 \mathrm{~N}^{\mathrm{o}}$ 3, dezembro, 2013. Disponível em: < https://seer.ufrgs.br/renote/article/view/44468>. Acesso em: 08 abr. 2019. 
MAZZARDO, M. D. Recursos educacionais abertos: inovação na produção de materiais didáticos dos professores do ensino médio. Tese de doutorado em Educação, especialidade de Educação a Distância e eLearning (EDeL) - Universidade Aberta de Portugal. Disponível em: <

https://repositorioaberto.uab.pt/bitstream/10400.2/7788/1/TD_MaraMazzardo.pdf>. Acesso em: 08 de fev. 2019.

MAZZARDO, M. D; NOBRE, A. M. J. F; MALLMANN. E. M. Small Open Online Course e Recursos Educacionais Abertos na Formação Continuada de Professores do Ensino Médio no Brasil. Indagatio Didactica, vol. 9 (2), julho 2017. Disponível em: < http://revistas.ua.pt/index.php/ID/article/view/5074>. Acesso em: 15 mai. 2018.

MORISSO, M. M.; VARGAS, T.G. ; MALLMANN, E. M. . A integração das tecnologias educacionais nas aulas de Educação Física do ensino médio de uma escola pública: resultados de uma pesquisa-ação. RENOTE. REVISTA NOVAS TECNOLOGIAS NA EDUCAÇÃO, v. 15, p. 1-10, 2017. Disponível em: $<$ http://seer.ufrgs.br/index.php/renote/article/view/79265>. Acesso em: 26 maio 2018.

RIO GRANDE DO SUL. Secretaria de Estado da Educação/Departamento Pedagógico. Referenciais Curriculares do Estado do Rio Grande do Sul: Linguagens, Códigos e suas Tecnologias / Lições do Rio Grande. Porto Alegre: SE/DP, 2009, v. 2. p. 113-181.

RIO GRANDE DO SUL. Secretaria de Estado da Educação/Departamento Pedagógico. União dos Dirigentes Municipais de Educação. Referencial Curricular Gaúcho: Linguagens. Porto Alegre. Secretaria de Estado da Educação. Departamento Pedagógico, 2018. V1.

SCHNEIDER, D. R. Prática Dialógico-Problematizadora dos Tutores na UAB/UFSM: Fluência Tecnológica no Moodle. Santa Maria: Universidade Federal de Santa Maria, 2011. 185f. Dissertação de Mestrado.

SCHNEIDER, D. R; MALLMANN, E. M; FRANCO, S. R. K. Fluência tecnológica dos tutores no moodle: potencial para prática dialógico-problematizadora. Em rede Revista de Educação a distância. 2015, v. 2, n. 2. Disponível em: < https://www.aunirede.org.br/revista/index.php/emrede/article/viewFile/63/87>. Acesso em: 08 abr. 2019.

SHIMABUKURO, J. SPOCs Are MOOC Game Changers. In Educational Technology and Change Journal, 2013. Disponível em: http://etcjournal.com/2013/09/26/spocs-aremooc-game-changers/ Acesso em: 15 mai. 2018.

UNESCO. Diretrizes para os Recursos Educacionais Abertos no Ensino Superior. 2015. Disponível em: <http://unesdoc.unesco.org/images/0023/002328/232852por.pdf $>$. Acesso em: 15 mai. 2018. 